\title{
Questions in Philosophy and Critical Thinking for Students
}

\author{
By Marija Liudvika Drazdauskiene*
}

\begin{abstract}
This paper elaborates on the concept of critical thinking as based on relevant questions and answers when thinking analytically rather than on how-to advice mentioned in the newest definitions. This concept is taken further while showing what questions mattered in philosophy (with the focus on the contribution of Socrates, Aristotle, Bertrand Russell, and the American general semanticists) and how they advanced knowledge. Apart from historical significance, the uses of the Aristotelian definition to students of English as a foreign language is highlighted in a digression with reference to definitions in modern dictionaries. Assuming that listening, understanding and questioning are the basic stages in critical thinking, it is stated in conclusion that it is only the person who has a deep understanding of the subject that can put relevant questions to assess and appreciate the subject, which is especially relevant in present-day world. This view and the historical overview raises requirements to critical thinkers and to higher learning. Well-developed knowledge in key spheres of communication and humanities is considered a requirement to all university $M A$ graduates and the duty of higher education to facilitate such knowledge.
\end{abstract}

\section{Introduction}

\section{Definitions of Critical Thinking as the Starting point in the Argument}

Critical thinking is considered in this paper in relation to its content and questions which mattered in philosophy and the quality of which can potentially inform it. Critical thinking is not primarily about criticism, as students sometimes wrongly assume. It may be identified with analytical thinking in which the knowledge, informed questions and the point of view of the questioner matter.

Critical thinking may be seen as an approach to or a treatment of what is heard, read or perceived with insight and question and answer while trying to understand it in depth and draw conclusions how reliable/acceptable and useful the content is. In Jon Stratton's (2019) concept, “The purpose of critical thinking is rethinking: that is, reviewing, evaluating, and revising thought" ${ }^{1}$. Although here, critical thinking is defined while focusing on the thinker rather than the reader, the concept does not contradict my own definition. Understanding in depth plays

*Professor, Wszechnica Polska, Poland.

1. Jon Stratton, "Critical Thinking - a crucial 21st century skill," Teaching English, accessed 8 September 2019, https://bit.ly/33Wx4iW. 
a role in any context but primarily in learning, while the ability to evaluate is helpful with publications in the media, especially with internet material.

Critical thinking is extensively explained by Edmund Dudley (2019) for Oxford University Press, ELT, online publication. Critical thinking, to this author, includes at least four key points: the belief that the information we are given should not always be accepted at face value; the idea that there is a difference between comprehension and understanding; the awareness that we are surrounded both by information and misinformation; the conviction that understanding is enhanced not only by getting answers, but also by formulating new questions ${ }^{2}$. Edmund Dudley makes a distinction between comprehension, which may be surface comprehension, and understanding, which may be deep if we think in a critical way. The points enumerated above can be credibly conceived only in thinking analytically.

\section{The Problem, Goals and the Character of this Paper}

The problem which initiates the present paper is a variety of interpretations of the very concept of critical thinking (CTh), which is widely current now, and the students' vagueness on the matter, as their reactions sometimes indicate. Critical thinking is not a new topic. It may have appeared about twenty years ago when students' ideas were vaguer and definitions rarer. In this paper, I intend to focus on the obligatory conditions in critical thinking, review major questions in philosophy, give ideas what we can learn from them and how they shape the content of CTh. This paper also gives advice how students should treat information and publications they read or happen to come across guided by critical thinking. CTh is important to the receiving person today when the spread of information is immense while responsibility for its quality is often taken by no one. Students, moreover, should be critical of and sensitive to the content and language even of their own papers, especially if they care for quality.

This paper is not a linguistic research paper. The task here is to show how the knowledge of the subject and essential questions formed innovative thinking in philosophy. The paper is therefore based on an overview of major classical and twentieth century philosophers who advanced this field of knowledge. The goal of the paper is to suggest that critical thinking should be based on informed questions arising from the knowledge of the subject and interest in it rather than on a few pieces of advice how to think. It must be the aim of higher education to create conditions of learning in which the students could develop substantial knowledge not only in the subjects of their field but also in such humanitarian subjects as forms and genres of communication, principles of writing in journalism, scholarship/science and imaginative literature, routine, public and

2. Edmund Dudley, "Critical Thinking as a Life Skill," Oxford University Press ELT, accessed 7 June 2019, https://bit.ly/3bFydOF. 
informative speaking. As all of these areas are related to the use of language, the article may ultimately contribute to the value of the humanities.

\section{The Analytical Concept of Critical Thinking}

\section{Conditions in Critical Thinking and background References}

The first condition in critical thinking (CTh) is the understanding of information in depth. So, this requires listening ${ }^{3}$ and thinking. This book of reference is not written specifically for the classroom. The author's references come from American social and political history. She argues that even socialpolitical conflicts may be resolved if the participants make attempts to really understand one another and to argue with reason, measure and conviction. Her principal idea applies anywhere. The author claims that listening produces a transformative effect on the audience, which is remarkable both to the person who addresses the audience and to the one who hears and realises that "we have lost the ability to listen" ${ }^{\prime \prime}$. This is true not only of kindergarten generations but also of many responsible adults who switch off because of the overflow of information or strain. Bobette Buster's book ends in an appreciation of the wonder and pleasure of being heard, which is part of wellbeing, of discoveries and fulfilment: "Being heard is so close to being loved that for an average person, they are almost indistinguishable" ${ }^{\prime \prime}$. Listening is key to understanding and both are important in critical thinking, while being heard is an acknowledgment. That is why this book has been chosen for reference in the present paper.

Understanding and motivated responding have been sought and so important in public communication that government offices required the following: "Put listening, responding and understanding in the centre of communications alongside with providing information." Everyone who is interested in communication taking place will accept the above recommendation. It has also been known that George Bernard Shaw had noted that the paradox of communication is the belief "that it has taken place." Indeed, communication may be well intended but it does not always take place, even in the classroom So, the condition of listening and understanding first, remains the key condition in good education and in CTh, especially that it is in line with "the chief use of humanistic studies, (which) is to explain, to understand, to appreciate"6 .

\footnotetext{
3. Bobette Buster, Do/LISTEN/Understand what's really being said (The Do Book Company, 2018).

4. Ibid, 21.

5. David Augsburger, quoted in Bobette Buster, Ibid, 95.

6. Paul Goodman, Speaking and Language. The Defence of Poetry (New York: Random House, 1971), 137.
} 
The second condition in CTh is asking the right questions. This entails correct questions verbally, which are relevant to the context of situation. It is the hearer/reader's interest that leads to questions. Appropriate questions happen to be asked by those who are familiar with the subject and the best questions by those who know the answer. In sciences, familiarity with the subject is a must. Edmund Dudley (2019), who published on the OUP website, contends that "successful learners are the ones with the right questions, not the ones with the right answers" 7 . Asking questions in routine, requires general education, awareness and some familiarity with reality and existence. So, a historical view of questions in philosophy might give ideas but it should be borne in mind that present-day concerns are the concerns mainly with television interviews, discursive prose and journalistic writing.

\section{Insights from the Major Philosophers}

\section{The Power of Questions in Research}

Asking relevant questions has driven science and philosophy for ages. For instance, some twentieth-century linguists suggested the following: "Ask an impertinent question and you'll get a pertinent answer", which means the result empowering one to go on further from the conceived conditions and known results. This, in a sense, is true as breakthroughs in science are usually achieved by questioning the given from an unexpected angle. But the question has to be motivated and relevant.

Experienced scholars advising students require that the students know the question which his paper is tackling. If there is no such research-driving question or problem, the paper should not be written. A research paper cannot be just a piece of writing about something, nothing, everything.

\section{Epoch-making Questions}

Whole epochs were known to have pondered some key questions. WHY was the question of classical antiquity when philosophers focused on causes and reasons in their concepts of the world and man. HOW was the question of the Renaissance when philosophers and artists kept pace with the rebirth of the models of classical antiquity in art and literature. Renaissance man focused on the ways things and phenomena happened and on the ways of managing them. It is not entirely wrong to assume that the question of the twenty-first century is HOW MUCH/MANY. This is formal and very pragmatic compared with the ageold questions of classical antiquity and the Renaissance. Such a question also

7. Dudley, "Critical Thinking as a Life Skill". 
indicates the focus on present-day quantities, as if statistics could solve problems of evolution and causes. Another question which bothers modern man is the question, Who are we? ${ }^{8}$. In his article in The Guardian, Tom Clark reviews what thread of preoccupation can be traced in different epochs: it is truth in ancient Athens, beauty in Renaissance Europe, political "reason" during the Enlightenment and scientific progress in the industrial age. But he claims that today professionals both in sciences and humanities are concerned with the question of identity rather than with specific questions in their specific fields.

\section{Questions that Mattered in the Progress of Philosophy: Socrates' Questioning and the Method}

It is said that Socrates (470?-399 BC), "the wisest man on earth" in modern Greek understanding, is remembered for his Socratic method, which "laid the ground work for Western systems of logic and philosophy, delivering a belief that through the act of questioning, the mind can manage to find truth." 9

The problem related to the Socrates's method is that Socrates left no written works. His conception and method are drawn from his student Plato's (429-347 BC) works, Dialogues, all of which have been preserved. The early Dialogues of Plato portray Socrates as questioning the false claims to knowledge of his contemporaries. Incidentally, the definition of knowledge, which takes up with Socrates reasoning and which has survived to the present-day, says that knowledge is "true belief plus a logos", i.e. rational confirmation ${ }^{10}$. Other sources define the Socratic method as "the dialectal method of teaching or discussion used by Socrates, involving the asking of a series of easily answered questions that inevitably lead the answerer to a logical conclusion foreseen by the questioner"11. This method of leading a student to the answer by consecutive questions has been recently renewed by some authors of pedagogical thought without the acknowledgment of its original author.

There is much to learn from Socrates. For instance, Plato's (Platonas) work, Phaedrus ${ }^{12}$, represents Socrates discussing and questioning the nature and kinds of the soul and the quality of rhetoric. Here we learn that Socrates repeatedly questioned Phaedrus what makes a good speech. His own answer was that the

8. David Robson, "The science of influencing people", The Guardian, accessed 1 July 2019, https://bit.ly/2X7XZqX. Tom Clark, "Revealed: the three-word question consuming the world's biggest brains", The Guardian, accessed 21 July 2019, https://bit.ly/3avA5Jv.

9. "12 Famous Philosophers and Their Guiding Principles", accessed 11 June 2019, https://bit.ly/3dHbdjX/

10. Simon Blackburn, The Oxford Dictionary of Philosophy (Oxford, New York: OUP, 1996), 123.

11. David B. Guralnik (ed.), Webster's New World Dictionary (New York: The World Publishing Company, 1974), 1352.

12. Plato/Platonas, Faidras (Phaedrus) (Vilnius:Aidai ALK, 1996). 
first requirement was to discover truth about the object of a speech and, second, to be able to define concepts in the argument with reference to the discovered truth $^{13}$. Third, the speaker should be responsible for all the ultimate concepts to be well-defined in his argument. The problem was that Socrates was familiar with the conception that truth was not considered obligatory in rhetoric where influence could be achieved merely by the clever use of words. Fourth, Socrates argued that to achieve an appeal, the speaker should study the nature of the soul and kinds of souls, as well as kinds of any objects to be able to select the most relevant, appealing and influential means of verbal expression ${ }^{14}$.

While questioning what makes the art of rhetoric, Socrates answered that he finds it praiseworthy when speakers are able to speak and think, to overview their subject and, focusing on prominent single objects, to classify them into kinds and to single these out. He called such speakers dialecticians and thought it wrong to discard dialectics ${ }^{15}$. Classifications was a strong point in antiquity. Socrates argued further that, irrespective of the question or subject in rhetoric, examples in a speech have to be sufficient, and empty words forbidden ${ }^{16}$. The moderns may conclude that, to judge wisely of a speech or a journalistic article today, the student has to identify a clear and substantial subject, an analytical focus on it, supporting facts and reasons, to believe it.

Socrates questioned minding two sides of every object - the good and the bad, trifles and important thing ${ }^{17}$, the moving and the static ${ }^{18}$, godly and human nature of the soul ${ }^{19}$, the manic and the mantic ${ }^{20}$, godly and human inspiration ${ }^{21}$, so that his all questions encompassed wholly the object of discussion.

Socrates put questions at the beginning and the end of his entry, so that he viewed the subject analytically rather than formally or routinely. As he went on, Socrates answered his own questions.

Socrates's answer to the question in what rhetoric the power of the speaker's influence was stronger - in that in which the speaker orientates himself well or in that in which he blunders, was that it was the speech in which the orator blunders without a track ${ }^{22}$. Such were supposedly the cases when the orator spoke under an impulse rather than according to a fixed line. The moderns must assume, therefore, that Socrates valued extempore speeches.

Finally, considering the quality of speech, Socrates claimed that every speech

13. Ibid, 92,96 .

14. Ibid.

15. Ibid, 73,74 .

16. Ibid, 67 .

17. Ibid, 64 .

18. Ibid, 41.

19. Ibid, 40 .

20. Ibid, 39 .

21. Ibid, 40.

22. Platonas, Ibid, 68. 
should be composed "like a living body" and have a head and legs, the body and limbs, and its all organs should stand in harmony and wholeness.

When answering his own questions concerning the verbal side of a speech, Socrates required that a speech be given in correct language ${ }^{23}$, be consistent in nature ${ }^{24}$, uniform ${ }^{25}$ and of moderate length ${ }^{26}$. Socrates said that every speech should have an introduction, development and its testimony, factual proof and credible argument, followed by a confirmation and its variant repeated ${ }^{27}$.

Socrates was sceptical about famous orators like Thessias and Gorgias of his time who considered that the credible are more worthy than the truthful, that a speech has a more powerful influence if minor things are magnified and the great are minimized, the old treated as the new and the new as the old. Although some of these criteria in and requirements to speeches were borrowed from the known orators, Socrates gave them his own interpretation. The principles mentioned above may well be applied in assessing analytically present-day journalism, interviews, political speeches and publicism.

\section{Plato's Questions}

Plato questioned the nature of the human soul, the vagaries of human nature and emotions, and focused on forms in the most general sense, and so Plato's philosophy is all aesthetic ${ }^{28}$. Plato contemplated the existence of the soul, of ideas and forms which are independent, real, divine, invisible and changeless, float in the space of being and are key to physical nature. Ordinary things 'participate' in or 'imitate' forms; the forms of things are ineligible and abstract features. There can be a difference in how physical and ethical things approximate forms. Round things may not be perfectly round, rather to approximate the ideal of roundness which itself may not be found in the world. Similarly, actual human institutions "may only approximate to the ideal of justice". But it is the ideal or form of justice that "provides an ineligible dimension of description and criticism" 29 . Knowledge of the forms should be sought by intellect and, when gained, gives sense to the world, otherwise unstable and deceptive. In philosophy, this is interpreted as the concept of how universals are present in particulars, although, in Plato's philosophy, it is the idea that is imitated by particular things ${ }^{30}$. Knowledge then,

23. Ibid, 75 .

24. Ibid, 77 .

25. Ibid, 79 .

26. Ibid, 75 .

27. Ibid, 74 .

28. Henrikas Zabulis, The Aesthetics of Classical Antiquity (Vilnius: Vilnius University, 1995).

29. Simon Blackburn, The Oxford Dictionary of Philosophy (Oxford, New York: Oxford University Press, 1996), 144.

30. Ibid, 289. 
in Plato's conception, is given a priori and has to be sought rather than derived by experience, confirmation and inference.

\section{Aristotle's Questions}

Plato's pupil Aristotle (384-322 BC) studied nature, legal practice, rhetoric, ethics and politics and so his all philosophy is $\operatorname{logic}^{31}$. Aristotle is assessed "as the first great logician", who is further recognised for "Aristotelian or traditional logic (of the syllogism), which dominated the subject until the nineteenth century" ${ }^{32}$. The syllogism is a form of deductive reasoning in which one proposition is inferred from two premises. For example: All phenomena have causes. Climate change is a phenomenon. Climate change has causes. This can be formally represented as when $A$ is $B$ and $C$ is $A$, so $C$ is $B$. As implied by this example, each premise has one term in common with the conclusion, and one term in common with the other premise ${ }^{33}$. It is generally acknowledged that correct premises ensure the correct conclusion. These regularities outline the rules of correct reasoning. They are not about processes in the mind, rather about formal reasoning, i.e. about the rules of drawing correct inferences from the given premises. There is a difference of how the correctness of the premises is confirmed: whether according to Plato, when the confirmation would have to be drawn from a priori knowledge, or according to Aristotle, when the confirmation would have to come from the observed detail of natural phenomena, including those of thought, language and psychology ${ }^{34}$. This is in line with Aristotle's conception of nature, his distinction between celestial phenomena and sublunary nature, as well as his "conception of perception as a literal sharing of form with that which is perceived"35.

\section{Aristotle's Definition and the Syllogism}

Apart from the syllogism, Aristotle has left the concept of definition which has remained in use to this day. Aristotle's definition is a classifying definition. For example: "A Democracy is a form of government under which the citizens distribute the offices of state among themselves by lot, whereas under oligarchy there is a property qualification, under aristocracy one of education. By education I mean that education which is laid down by the law; for it is those who have been loyal to the national institutions that hold office under an aristocracy." 36 "These are bound to be looked upon as

\footnotetext{
31. Henrikas Zabulis, The Rhetoric of Classical Antiquity (Vilnius: Vilnius University, 1995a).

32. Blackburn, Ibid, 221.

33. Ibid, 368-369.

34. Blackburn, Ibid, 25.

35. Ibid.

36. Aristotle, Rhetoric, Book I.8 (New York: The Modern Library, 1954), 33-36.
} 
'the best men', and it is from this fact that this form of government has derived its name ('the rule of the best'). Monarchy, as the word implies, is the constitution in which one man has authority over all." 37 .

This is the typical style of writing and reasoning by Aristotle in the English translation of Rhetoric. This philosopher gives definitions of the words and terms he uses at every step. The essence of his definition is the identification of the word defined with its class category: democracy is a form of government; by education I mean that education which... Monarchy is the constitution... This shows how classifying definition works: the term/word is classified by its category with descriptive features added up. Causes and classification make the time-tested heritage of classical antiquity. This definition has been retained in numbers of countries of Western culture and, specifically, in dictionaries to this day. For example:

democracy 1. Government in which the people hold the ruling power either directly or through elected representatives; rule by the ruled ${ }^{38}$.

democracy 1 . A system of government in which all the people of a country can vote to elect their representatives ${ }^{39}$.

Syllogistic reasoning was questioned in English philosophy in the $18^{\text {th }}$ century ${ }^{40}$, yet remained an academic subject down to the $20^{\text {th }}$ century. "Syllogistic reasoning is now generally regarded as a limited special case of the forms of reasoning that can be represented within the propositional and predicate calculus $^{\prime 41}$. Indeed, a scholarly work based entirely on syllogistic reasoning like the book Understanding Sentences by Diane Blakemore ${ }^{42}$ reads like an argument with a limited potential. Reasoning in the modern logical mode involves a broader spectrum of propositions. It was logical positivism representatives of which argued for modern logic which is known as mathematical logic. Modern logic in mathematics is formal and universal. Its principle is explained in the humanities as the kind of reasoning in which "on the basis of a single experience, a number of verbal statements are justifiable" 43 . This practically sums up as an extension of the postulates of syllogistic reasoning where it is possible to draw one conclusion from two premises. In mathematical reasoning, it is possible to draw as many conclusions from two premises as can be practically proven.

Logical positivism of the $20^{\text {th }}$ century introduced the verification principle in logic,

37. Ibid, 36-40.

38. Guralnik, 375.

39. Sally Wehmeier (ed.), The Oxford Advanced Learner's Dictionary (Oxford, New York: OUP, 2005), 406.

40. John Passmore, A Hundred Years of Philosophy (New York: Penguin, 1978).

41. Simon Blackburn, 221.

42. Diane Blakemore, Understanding Sentences (Oxford: Basil Blackwell, 1992).

43. Bertrand Russell, An Inquiry into Meaning and Truth (Harmondsworth: Penguin, 1965), 19. 
which was about a "denial of literal or cognitive meaning to any statement that is not verifiable". This idea was in accord with their premise that "the meaning of a statement is its method of verification" ${ }^{\prime 4}$.

\section{Questions Challenging Syllogistic Reasoning}

In the twentieth-century, American general semanticists, who represent linguistic philosophy, attacked Aristotelian syllogistic reasoning on four counts: 1) proposition; 2) definition; 3) predictive value, and 4) logical conundrums. They raised the question of how to solve conundrums of syllogistic reasoning and perhaps how to update Aristotelian logic (of the syllogism and the enthymeme, i.e. of an argument in which one premise is not explicitly stated. The enthymeme is the key concept in Aristotle's Rhetoric), which held sway for over two thousand years without alterations. "Logic was considered largely a closed system (...) and was taught in Western universities in much the same way Aristotle had taught it about 350 BC." 45 .

American general semanticists and the British philosopher Bertrand Russell, showed and proved that the propositional function rather than the proposition is essential in reasoning. It was a belief of classical or Aristotelian logic that "all judgments could be broken up into simple propositions, that is, statements in which something (a predicate) is asserted about something (a subject). Examples are water is wet; grass is yellow; some Greeks are rich; no animal is rational. It was also assumed that such propositions were either "true" or; "false": water is wet is a true proposition, grass is yellow a false one. Logic was a set of rules for deriving propositions from other propositions" ${ }^{\prime 4}$. The proposition was questioned on the grounds that, though some assertions grammatically are propositions (a predicate is asserted about a subject: $x$ is green), "they cannot be said either true or false. If $x$ is grass, it is true, but if $x$ is milk, it is false" ${ }^{\prime \prime}$. This replacement of a word by a symbol led to the concept of propositional function with its origin in mathematics. When symbols stood for propositions, classical logic became symbolic logic which entailed the propositional function and made logic part of mathematics. Apart from this, general semanticists proved that "practically all our judgements are made not in terms of propositions but in terms of propositional functions" ${ }^{\prime \prime}$. The truth of statements like grass is yellow, "which looks like a proposition", depends on what kind of grass is meant and what kind of yellow is meant and leads to the second count in the challenge to Aristotelian logic, that is, to the meaning the

44. Blackburn, 223.

45. Anatol Rapoport, "What is Semantics?" In The Use and Misuse of Language, ed. S.I. Hayakawa (Greenwich, Conn: A Fawcett Premier Book, 1962), 16.

46. Ibid, 16.

47. Ibid.

48. Ibid, 17. 
speaker assigns to the words used.

In a simpler form, this is the question, "What do you mean?" and a lead to the concept of predictive value. The proof of or criteria to the facts such as grass is yellow or the earth is round are not direct; the proof may be deduced indirectly or predicted from the known experience. It was Bertrand Russell who determined that truth is primary and knowledge is secondary, and that truth can be confirmed by observation, experiment or logical reasoning by basic propositions, which would be the case for the above mentioned examples. So predictive value becomes a criterion of truth. At this point, however, the requirement to consider definition is also obvious.

\section{The Development of Aristotle's Definition}

As mentioned above, Aristotle's definition was a classifying definition: it ascribed a thing to a class and added up features which distinguished the thing from other members in the class. In contrast to the Aristotelian classifying definition, general semanticists proposed an operational definition. The operational definition "tells what to do to experience the thing defined"49. In other words, the operational definition determines a thing's function and thus explains what kind of thing it is. Referring to physics, general semanticists drew attention to the fact that physicists define terms "by telling how to proceed and what to observe": the coefficient of friction can have the following definition: "If a block of some material is dragged horizontally over a surface, the force necessary to drag it will, within limits, be proportional to the weight of the block. Thus, the ratio of the dragging force to the weight is constant quantity. This quantity is the coefficient of friction between the two surfaces." 50 Verbs are similarly defined in a general dictionary. For example:

speak, $\mathrm{v}-1$ to talk to $\mathrm{sb}$ about sth; to have a conversation with sb $\mathrm{s}^{51}$

implore, $\mathrm{v}$ (formal or literary) - to ask $\mathrm{sb}$ to do sth in an anxious way because you want or need it very much SYN: beseech: She implored him to stay ${ }^{52}$

These definitions do include a description of the process because the words are verbs. Definitions of nouns in the same dictionary are semi- functional in modern dictionaries as they include a description of a process and some additional features. For example:

company, $\mathrm{n} 1$ (often in names) a business organization that makes money by

49. Ibid.

50. Ibid, 18.

51. Wehmeier, 1467.

52. Ibid, 779. 
producing or selling goods or services: the largest computer company in the world; 2 a group of people who work or perform together: a theatre/dance company; 3 the act of being with sb else and not alone: I enjoy Jo's company; 4 (formal) guests in your house: I didn't realize you had company; 5 (formal) a group of people together: She told the assembled company what had happened 6 a group of soldiers that is part of a battalion. ${ }^{53}$

Like the meaning of a process in these definitions, the claim of the American semanticists on account of the Aristotelian definition was also only partly true because Aristotle used functional definitions in his Rhetoric, so the semanticists only highlighted what was in the shade in Aristotle's own writing. For example:

Political speaking urges us either to do or not to do something: one of these two courses is always taken by private counsellors, as well as by men who address public assemblies. Forensic speaking either attacks or defends somebody: one or other of these two things must always be done by the parties in a case. The ceremonial oratory of display either praises or censures somebody. These three kinds of rhetoric refer to three different kinds of time. The political orator is concerned with the future: it is about things to be done hereafter that he advises, for or against. The party in a case at law is concerned with the past: one man accuses the other, and the other defends himself, with reference to things already done. The ceremonial orator is, properly speaking, concerned with the present, since all men praise or blame in view of the state of things existing at the time, though they often find it useful also to recall the past and to make guesses at the future. ${ }^{54}$

Happiness in old age is the coming of old age slowly and painlessly; for a man has not this happiness if he grows old either quickly, or tardily but painfully. It arises both from the excellences of the body and from good luck. ${ }^{55}$

But cf.: 'Good luck' means the acquisition or possession of all or most, or the most important, of those good things which are due to luck. ${ }^{56}$

\section{The Uses of Aristotle's Definition}

As the illustrations above show, Aristotle's definition of 'democracy' has verbally remained the same for over 2000 years, with only a few words varying in it. The definitions of common words in Anglo-American dictionaries are of the same kind, and a digression on the uses of the classifying definition may benefit the students of English as foreign language. Cf.:

53. Wehmeier, 306.

54. Aristotle, Ibid, Book I. 3, 32.

55. Ibid, Book I. 5, 41.

56. Ibid. 
assistant, $\mathrm{n}$ 1) a person who helps or supports sb, usually in their job ${ }^{57}$ doctor, $\mathrm{n} 1$ ) a person who has been trained in medical science, whose job is to treat people who are ill/sick or injured; 3 ) a person who has received the highest university degree ${ }^{58}$

crook, n 1) (informal) a dishonest person SYN criminal; 3) a long stick with a hook at one end, used especially in the past by shepherds for catching sheep ${ }^{59}$ assistant, $\mathrm{n} 1$ ) a person who assists or serves in a subordinate position; 2) a thing that aids ${ }^{60}$

doctor, n 1) (origin) a teacher or learned man; 2) a person on whom a university or college has conferred one of its highest degrees, either after he has fulfilled certain academic requirements or as an honorary title; 3) a physician or surgeon; 4 ) a person licensed to practice any of the healing arts, as an osteopath, dentist, veterinarian, etc $(+5,6,7 \text { definitions })^{61}$

crook, n 1) a hooked, bent, or curved thing or part 2a) a shepherd's staff, with a hook at one end b)a bishop's staff resembling this; crosier 5) (colloq.) a person who steels or cheats, swindler or thief ${ }^{62}$

communication, $\mathrm{n} 1$ ) the activity or process of exchanging ideas and feelings or of giving people information; 2) pl methods of sending information, especially telephones, radio, computers, etc or roads and railways; 3) (formal) a message, letter or telephone call: a communication from the leader of the party ${ }^{63}$

communication, $\mathrm{n}$ 1) the act of transmitting; 2a) a giving or exchanging of information, signals, or messages by talk, gestures, writing, etc; b) the information, message, etc; 3) close, sympathetic relationship; 4) a means of communicating; specif., a) $p l$ a system for sending and receiving messages, as by telephone, telegraph, radio, etc; b) $p l$ a system as of routes for moving troops and material; c) a passage or way for getting from one place to another; 5) often $\mathrm{pl}$, with $\mathrm{sg} v$. a) the art of expressing ideas, esp. in speech and writing; b) the science of transmitting information, esp in symbols ${ }^{64}$

These definitions are similar as they all classify the word defined by a certain category: assistant, doctor, crook are all a person who is characterized by his qualification, position and/or functions

The shorter definitions are drawn from the Oxford Advanced Learner's Dictionary, which is a student dictionary; their brevity ensures their clarity. The
57. Wehmeier, 79.
58. Ibid, 450.
59. Ibid, 365.
60. Guralnik, 84 .
61. Guralnik, 414.
62. Ibid, 337.
63. Wehmeier, 304.
64. Guralnik, 287. 
longer definitions are drawn from Webster's New World Dictionary, which is an encyclopedic dictionary and contains longer and more specific definitions. But the definitions follow the same rule, they classify the concept by category: communication is the activity or act of transmitting/exchanging information, etc.

The definitions thus structured have several merits: they train the user's sense for the language and can improve language skills. Classifying definitions in Anglo-American dictionaries also prompt, to the user, conceptual categories in the language: the category by which the word is identified (an assistant, doctor, crook are persons, while crook can also be a staff. The defining category of the noun matters when the user has to use the word, because the category prompts how concrete or abstract the word is and what modification by the article it requires. This is also in line with the analytic clarity of English, as the classifying/defining category prompts how the word may acceptably combine with other words, i.e. how concrete and clear the words in collocations should be. Cf.: assistant can be capable, patient, trained, temporary, etc; doctor can be capable, learned, resourceful, talented, discreet, etc; crook can be dirty, filthy, ordinary, capable, etc; communication can be efficient, swift, economical, constant, continuous, anonymous, confidential, etc assistant can be temporary and permanent, but not constant; constant can be a friend and communication. When looking into the meaning of these words deeper, it is possible to trace the exact semes which keep the words together. For instance, as permanence means a limited time, the adjective permanent applies to assistant and job, whereas as constant means a moral quality, this adjective combines with friend and communication. Definitions in Anglo-American dictionaries well orientate a clever user according to the classifying word in them. When looking up words, it is advisable to pinpoint the classifying word in their definitions first of all and only then to use the word. Style labels to the word are also important. This digression has been for the benefit of the learners of English as a foreign language to indicate that, if taken in, the Aristotelian definition may develop not only the skill of speaking but also the insight of the mind. I hope it was not entirely useless.

\section{A Further Development of Aristotelian Logic}

The fourth point made by the American general semanticists was the point of logical conundrums in syllogistic reasoning such as All sentences in this square are false. Syllogistic reasoning was finished on this: if all sentences are false, this one must be true. There was no go to resolve this issue in syllogistic reasoning. The case was resolved by the theory of types which claims that "a class cannot be a member of itself" 65 . American general semanticists worked out further concepts such as the principle of non-identity, the principle of non-allness and the principle of self-reflexiveness in logic, and their less formal contributions have been

65. Rapoport, 19. 
mentioned above.

This brief sketch indicates that the questions in general semantics, epistemology and logical positivism have focused on ample data of science and their modern interpretation. The source of the questions has been like that adopted by mathematicians who admit even today that they discover data but then invent the instruments for thinking about the data and sharing it. Representatives of the above-mentioned fields followed the same line of reasoning which Bertrand Russell confirmed in his assumption of the priority of truth over knowledge and its confirmation by experience or logic while centring on basic propositions. The philosophers questioned established conceptions on the basis of their essential knowledge of and their insights into them.

\section{Enabling a Critical Thinker}

\section{An approach to the Form of questions}

Except for such cases as the epistemological question, Why should I believe it? or What is the value of this piece of knowledge?, questions in sciences and philosophy required exceptional familiarity with the subject in its prior state. Only then can questions be forward-leading. The practice of asking questions in $\mathrm{CTh}$ is of a slightly different character. Whether students, accomplished professionals or laymen, they all encounter publications and messages of a minor scope, usually in the language commonly understood the content of which is supposed to be accessible to them. The task is not only to perceive that content but think it over, question it and evaluate it in order to determine its value either in general or for oneself personally. When students desire to know how to approach multitudinous publications for value judgments, advice may be gleaned again from older books or ancient philosophers. Although the book, The Art of Asking Questions, by Stanley L.Payne ${ }^{66}$ is based on reassessing questionmaking in surveys and some of its content may be useful to teachers, a few points made by the author may be relevant to students in CTh. Throughout the book, Stanley Payne reiterates the statement that a question and its wording are inseparable and that the success and result depend on the words in the question. Even if questions in CTh may often be only mental and silent, a clear wording does matter because it requires clear brain and may discipline and train the student, especially in so far as English is concerned. Stanley Payne's second principle is "clarity for cleverness", which means to be critical toward one's own questions" ${ }^{\prime 67}$. In other words, no questioner should take pride in his own wording

66. Stanley L. Payne, The Art of Asking Questions (Princeton: Princeton University Press, 1973).

67. Ibid, 16. 
before he makes his question really clear to others. A third principle borrowed from this author would be the implied value of the question, which is "in knowing the points for which to test" (i.e. enquire) ${ }^{68}$. This is the piece of advice to know what to ask about. These rules can and perhaps should be utilised by the student in CTh to know how to approach the avalanche of often biased publications.

\section{Classical Approaches to the Evaluation of Speech}

A time-tested piece of advice can be gleaned from authors of classical antiquity who deliberated rhetoric, wrote on it and left their opinion on how to approach rhetoric or public speaking in which "anything may be proven with the help of words". Theophrastus determined a speech by three points: word order, harmony of development and stylistic devices. This author added three requirements to sublimity: elegance, the patterning of words and nobleness of thought and words. Aristotle maintained that rhetoric should be easily perceivable and the words well chosen ${ }^{69}$. This may be relevant today when we think of journalists' writing and fake news.

Authors of classical antiquity also warned against false speeches and gave advice on this point. They noted the features which indicate whether a speech is true. They are: 1)logic, 2)the appropriateness of words, 3)the words of authoritative authors (quotes and maxims) and 4)the customary use of words. Aristotle pointed out the following of a true speech: 1)clarity as stylistic perfection, 2)direct word order, 3)the end in the right place rather than put off too far, and 4)nothing in excess. Cicero noted 1)brevity, 2)potentiality and 3) being suave, as the points of proof of a true speech. 'Suave' meant pleasantly disposed, to the ancients. ${ }^{70}$ Today, this word means "confident, elegant and polite, sometimes in the way that does not seem sincere" 71 . We can assume that a true speech should be clear beyond doubt, unambiguous not to confuse, its language should be balanced and the composition straight. Rare, vague and evaluative words, especially if too many, should arouse suspicion today, in the age of fake news. Even guided by these principles and contemporary criteria, we might bear in mind that there have appeared publications claiming that although fake news has its price, it is dangerous to assume that somebody may be the keeper of 'the truth $^{\prime 72}$. The idea is that there was fake news from single sources (or parties),

68. Ibid, 13-14.

69. Henrikas Zabulis, The Rhetoric of Classical Antiquity (Vilnius: Vilnius University, 1995a).

70. Ibid.

71. Wehmeier, 1528.

72. Kenan Malik, Fake news has a long history. Beware the state being keeper of 'the truth', The Guardian, accessed 11 February 2018, https://bit.ly/2wRVHRR. 
which we have survived, so that fake news from variable sources today may just be a variation on the known theme and can be tackled rationally.

\section{Specimen Analysis}

To give an idea of how to approach a publication analytically applying the skills of CTh, I would suggest focusing on a short article, The perils of learning in English, published in the Economist this year ${ }^{73}$.

The title of this short article initiates a question, Is it really dangerous to learn in English or does the title merely overstates for emphasis? This is a relevant question as the gist line under the title, (Young children should be taught in their mother tongue instead), is an imperative for learning in the mother tongue at a young age.

The following questions might be relevant when reading this article analytically.

1. What does the emphatic framing of the article by references to the success of Winston Churchill mean? Is it the pitch of the argument or only a rhetorical device with a shade of tongue-in-cheek that recurs in the article and tends to irony?

References to the success of Winston Churchill make the overall point of the benefits of learning the mother tongue and of learning in the mother tongue. The great success of the great Prime Minister only emphasises the role of the mother tongue and frames up the article the classical way. It is also the pitch of the argument made credible in an elegant way.

2. How convincing is the argument when it is not verbally thorough and rather consists of a review of facts with some comments which are not generalized to pin-point the author's statement?

It is the style of the author of the article to use facts without pin-pointing generalisations, and this is more convincing than point blank conclusions.

Cf.:

$\S 2$ states the fact of numbers.

$\S 3$ is about the praiseworthy global spread of English which rounds up in a tongue-in-cheek remark of the benefits for the present newspaper.

$\S 4$ is of the spread of English in education in the former colonies and rounds up in a reference to "a glittering world of professionals", which tends to irony.

73. The perils of learning in English, The Economist, accessed 29 February 2019, https:// econ.st/3dMDh5t. 
What is the point of this irony? The world of professionals is the world which "parents in the slums of Delhi" and other places see as the dream world for their children, while the author of the article, who obviously knows the value of its image and the value of the effort it requires, ironises its surface attractiveness by the word glitter. The irony is based on the difference between the concepts of those who know and those who only imagine the quality.

$\S 5$ is of administrative predilection of English as the medium of instruction in the former colonies too. What is the unstated conclusion? Is English as the medium of instruction good or bad? Why is it not stated? The facts with an occasional evaluating word in this paragraph are obvious enough to show the benefits of learning in the mother tongue and the falsehood of education authorities in "switching to English medium... to stem the outflow of children into the private sector". The author is true to his consistent point-of-view and his conclusions while bypassing plain generalisations only to gain trust from the reader as he would from the parents.

Like $\$ 2, \S 6$ is a statement of fact in brief sentences and a point-blank conclusion, which is another way of stating an undeniable fact in the present article.

$\$ 7$ confirms the research facts of the benefits of instruction in the mother tongue. The conclusion is tentative, "Perhaps this is because they gain a better grasp of the mechanics of reading and writing." How convincing is the argument in this paragraph? This paragraph is as convincing as any and even more so because of its subtle expository sense.

$\S 8$ draws the threads of the argument in imperative generalisations for parents and governments.

The recurrent should should be noted in this paragraph. How convincing and acceptable is its conclusion? The imperative sense in this paragraph and its plain conclusion of improving public schools by "limiting the power of obstructive teachers' unions" and "developing good curriculums" is a singular point-blank recommendation in this article and so is very credible.

Does it make a consistent logical statement or is it an overarching prescription? It is a consistent logical statement, if only emphatic by the contrast it makes.

And finally: Is it a trustworthy argument in good humour or is it a biased article? The argument in this article is trustworthy. No bias is implied, mostly because of the scarcity of point-blank generalisations.

Is the title factual or a hyperbole? The title is a moderate hyperbole, expressed by the word perils, which diminishes the implied imperative.

Is the article really about the perils of learning in English or about the benefits of learning in the mother tongue? The article is about both - the perils and the benefits in choosing the language of instruction for young learners.

To support my conclusion, I can add that I am familiar with the knowledge of some endurance that a foreign language imposed on a very young child before 
his concepts are formed formidably in his native language is damaging. Too early prescription of a foreign conceptual reality on a young mind may prevent him from developing the sense of the clarity of concepts in any language and from acquiring the clarity of thinking. Given this bit of knowledge, we can accept the conclusion about the reliability of the ideas in the article for granted.

If understanding followed by questions may be supported by truthful facts or knowledge, no authorities are required to support a critical thinker. Knowing what to ask is essential in forming questions. The relevance of questions matters contextually. One's prior knowledge is essential, but personal interests may prompt the right answer both verbally and contextually.

I must confess that I was looking for a really provocative article to be analysed in this paper, but I found none. Yet, I have analysed several articles to test the precepts and my convictions. I have not, as I said, found any really flawed publications which would represent fake news or biased journalism. But I have had a few that did not meet my expectations. For instance, I expected that the article, How language duped us into austerity written, by Zoe Williams ${ }^{74}$ will review ample linguistic material to show how authors in the media emphasise facts and processes beyond measure, how they slant their view in favour of official policies or how they explain economic and geophysical imperatives to affluent communities because a majority of sedentary communities do live in affluence. What was mentioned in the article was that researchers into "a relatively small number" of cases in England were looking for "images, metaphors, certainties and black holes" that recurred in the four interviews they studied. What was mentioned language-wise, was the necessity "to tighten our belts", "the most frequent metaphor" for the economy was "a bucket" into which "some people put in and others take out", that "market forces" were seen as mysterious while using the words "falling" and "tumbling" to describe processes in them. The verb "work" was typically used to denote economic processes, and the research showed a shocking implication of "ubiquity and level of fatalism". The conclusion was that terminologically levelled communication on economic matters kept the atmosphere "curiously buoyant" at the beginning of austerity and, as the process continued, people were left feeling "there (was) very little they (could) do and that general public had no role to play". This was how society was incapacitated in the context of unacceptable and volatile developments.

The spirit governing social attitudes was nostalgia for "an idealist past when wages were high, inequality was low and (people) were more "self-reliant"". It was only the erosion of the ideal past that was ascribed to coming "from elsewhere" The conclusion was that new terminology for sensible economic representation has to counter public confusion first rather than public convictions.

Another article that held my attention was The steam has gone out of

74 . Zoe Williams, "How language duped us into austerity," The Guardian, accessed 18 February 2018, https://bit.ly/33Z8LRH. 
globalization $^{75}$. This unsigned article is based on hard facts. It says that 2018 was not a bad year financially and economically: "global growth was decent, unemployment fell and profits rose". This was not the picture in 2017 when America turned to protectionism. But after a trade pact was signed with Mexico and Canada and with hopes related to a possible deal with $\mathrm{Xi}$ Jinping increased, it seemed that "the trade war" will possibly be treated as "political theatre" to squeeze "concessions from China" rather than detonate "global commerce". The author calls this attitude complacency which is mistaken because trade tensions compound "a shift that has been under way since the financial crisis in 20082009". The result is sluggish economies, which the author calls slowbalisation. The trading of goods has shifted to services, "which are harder to sell across borders". Rules of commerce have been changing around the world and gone is the attitude to treat firms equally irrespective of their nationality. Geopolitical rivalry is arresting tech industry and tax systems are being modified "to patriotic ends". Firms' long-term investment plans have been changing as they started avoiding countries with high geopolitical risk. Although "1.2 bn people have been lifted out of extreme poverty since 1990" and "western consumers will continue to reap large net benefits from trade", it is claimed hat "slowbalisation has two big disadvantages". First, it creates new difficulties and there is tension between "regional trading pattern and a global financial system." Second, "slowbalisation will not fix the problems that globalization created". Automation will require unskilled workers and blue-collar jobs will diminish. "Climate change. Migration and tax-dodging" will be harder to tackle "without global cooperation" and China's hegemony is likely to grow faster.

Ignoring the social-cultural grievances caused by migration, it stated that "globalisation made the world a better place for almost everyone". "But too little was done to mitigate its costs". The integrated world's neglected problems have grown and are not likely to go away of their own. It is predicted that slowbalisation will be meaner and less stable than globalization as it gradually turns to discontent.

Today, over a year later we read in business news that the markets have not really stabilised and are sensitive to America's present-day commercial-economic caprices, the dollar trades a little higher than the euro and there is little economic progress while stagnation is forecast for the smallest national economies.

This article attracted me by its title because I expected a humanitarian treatment of the topic. But it did not really disappoint me because the facts were true and reasonably presented. As it is only two pages long, it may be appreciated as a fair professional publication.

Sophia Ignatidou's article, The weaponization of information is mutating at

75. "The steam has gone out of globalization," The Economist, accessed 24 January 2019, https://econ.st/3aAQ7ll. 
alarming speed,76 argues that "communication has been weaponized, used to provoke, mislead and influence the public in numerous insidious ways". She believes that the number of countries employing disinformation is growing. The second stage in the process is "the increasing effort to control information flows and therefore public opinion", while the removing of accountable and experienced journalists can be only damaging "to the public interest". The third stage is linked to "mass-scale surreptitious manipulation through nudging", which creates "a tailored view of the world" .The cause of these processes is in disabling traditional media to resist "the hijacking of the news agenda by divisive actors seeking to amplify their agenda via clickbaity disinformation". The declaiming of media privacy and "resisting the information weapons being used to discipline and control media" might be a way out. This is a reliable article which objectively reviews processes in the media, its staff and information presentation. The argument is well-grounded and free from biased or stock views.

Another article in The Guardian concluded that, however attacked by fake news, American public can discriminate between facts and falsehood. As surveys and research show, American public does not evenly divide into two groups - the liberals and the conservatives. This shows in how intelligently the public can sort out the flow of information and make realistic judgments.

Finally, a recent article, The science of influencing people: six ways to win an argument, ${ }^{77}$ written by David Robson recommends to go beyond the "illusion of explanatory depth" when perceiving an argument so as not to take it uncritically. In perceiving an argument, we should not confuse "shallow familiarity" with "indepth knowledge". Shallow explanations may have false premises. They have to be approached with the question how: how can something be done? This question asks for more details, and shallow arguments fall apart. Another way to check unreliable argument or information is to make sure that an explanation offers "a convincing coherent narrative". Sources of misinformation can be helpfully discussed in this context. Many arguments which are linked to broad political beliefs of the contender may be helpfully straightened out if they are extricated from the broad and irrelevant political conviction that get in the way. Alternative factors may help in this removal of persistent and irrelevant beliefs that block the progress of thought. Taking an outsider's perspective on the problem may help to advance the argument. Finally, in order to win in a discussion, the speaker may advance by kindness. Rather than criticising downright the opponent's views, the speaker should be tolerant to the contrary opinion, which always disarms the opponent. A part of these recommendations can be helpful in viewing critically the available information, and all may be

76. Sophia Ignatidou, "The weaponisation of information is mutating at alarming speed," The Guardian, accessed 19 August 2019, https://bit.ly/2UXWeKe.

77. David Robson, "The science of influencing people: six ways to win an argument," The Guardian, accessed 1 July 2019, https://bit.ly/39EO1jq. 
helpful in arguments, the more so that they are in line with the advice known from classical antiquity. This overview has kept both in view.

\section{Conclusions}

In conclusion, here are a few generalisations. To be true to fact and to myself, I have to draw the audience's attention to how essential questions in philosophy were. The questions of all philosophers, beginning with Socrates, and the way the questions were put indicate deep and essential familiarity with the subject. That is why the questions confirmed truth and contributed to knowledge when answered. However challenging it may be, one conclusion would be that a student who desires to advance in critical or analytical thinking should be well familiar with the subjects which he intends to question. The student's higher education should have advanced his knowledge of numerous, especially humanitarian subjects so much that he is in possession of prior knowledge required in questioning. If such knowledge of regular forms and genres of communication, of discourse and communication principles is lacking before graduation, it may be improved in courses of "practical communication in English as a foreign language" or similar ones. But essential familiarity with spheres of current scientific and humanitarian thought, with regular forms and genres of communication is obligatory to everyone claiming a Master's degree in the humanities and sciences. Whoever is not in possession of such knowledge, cannot really advance in critical thinking.

There is also practical advice I have gleaned in the press and online, which can be helpful to orientate a person focused on critical thinking while knowing what to expect and where. A recent piece of advice online from BBC World Service (24 October 2019) was: "You should never trust commentators in political analysis. It is a very superficial analysis".

In the 2016 election in the USA, predictions of reporters of the election results were brushed aside by the following remark: "It is not the business of journalists to predict the outcome. It is generally unpredictable. The business of journalists is to report facts and draw reasonable conclusions". The student can be warned of the writing which forecasts the future, especially that there has also been a blunter evaluation on this account after the recent events in the Middle East, which accompanied the following announcements:

"This strike was aimed at deterring future Iranian attack plans," the Defence Department announced afterward. "The world is a much safer place today," Secretary of State Mike Pompeo intoned, sounding like the Minister of Truth. "I can assure you that Americans in the region are much safer."

Only ignoramuses and ideologues claim to know what's going to happen 
next, but one prediction I'm willing to make is that events will shortly obliterate these official statements. The strike had nothing to do with deterrence. Pompeo's own department is warning Americans in Iraq: "U.S. citizens should depart via airline while possible, and failing that, to other countries via land...."78.

Finally, on the $13^{\text {th }}$ of November 2019, there came an announcement on the HOW to ACADEMY website of a January event, titled, "Stop Reading the News (and enjoy a happier, calmer and wiser life)" - Rolf Dobelli in Conversation with Matthew d'Ancona, 13 January 2020. A suggestion was a news detox. Not to overestimate the message, I can confirm that numbers of educated people born before the television generation live while reading print news and listening to the radio and bypassing television, and they do not lag behind academics and media leaders with their knowledge.

The closing piece of advice would be to be selective. Being selective and discriminating is, on the one side, the aim of critical thinking. But, on the other, a student would do well if he thought before picking up a paper or opening a website and learned to select and discard, at the start. Critical thinking is also about learning to be discriminating and being cautious to shorten the way to wisdom while learning.

In addition to the rules and principles which I mentioned in the historical review, I can add a piece of personal advice. When I pick my reading online, I ask whether the topic is from the sphere of my interests. Then I think whether the title attracts me or makes me cautious. As you may have guessed from the overviewed articles, I am cautious about evaluative titles. If they attract me and if the article proves reliable, I reevaluate such titles and see in them only a journalistic turn of the phrase. Finally, I think whether the article was convincing and why and what the author's flaws were, if any. Evaluative words and subjective statements may be really indicative of flawed information or point of view.

Skills and advancement in critical thinking should be based on good listening and understanding in-depth. The rules from classical antiquity can well guide in assessing what we read or hear by paying attention to the logic of the argument, its proportional composition, the choice of common words and few of excessively used evaluative words, little emphasis on personal views and no slanting presentation. Questioning what one hears and viewing it analytically requires well-formed questions: this should be based on good knowledge of the subject to be able to put a relevant questions and to assess the reliability of the argument. In critical reviews of one's papers, the simplest questions may be helpful as they may indicate weak points or suggest a neglected or ignored point of discussion. In critical thinking, questions should be motivated and, to be relevant, they should be based on a really advanced knowledge of the subject.

78. George Packer, Killing Soleimani Was Worse Than a Crime. It was a blunder, accessed 4 January 2020, https://bit.ly/39vILOH. 


\section{Bibliography}

Aristotle. Rhetoric. Poetics. New York: The Modern Library, 1954.

Blackburn, Simon. The Oxford Dictionary of Philosophy. Oxford, New York: Oxford University Press, 1996.

Blakemore, Diane. Understanding Sentences: An Introduction to Pragmatics. Oxford: Basil Balckwell, 1992.

Buster, Bobette. Do/LISTEN/Understand what's really being said. Find a new way forward. The Do Book Company, 2018.

Clark, Tom. "Revealed: the three-word question consuming the world's biggest brains." The Guardian. Accessed 21 July 2019, https://bit.ly/3avA5Jv.

Dudley, Edmund. "Critical Thinking as a Life Skill." Oxford University Press ELT Accessed 7 June 2019, https://bit.ly/3bFydOF.

Goodman, Paul. Speaking and Language. The Defence of Poetry. New York: Random House, 1971.

Guralnik, David B. (Editor in Chief), Webster's New World Dictionary of American Language. $2^{\text {nd }}$ College Edition. New York: The World Publishing Company, 1974.

Ignatidou Sophia. "The weaponisation of information is mutating at alarming speed." The Guardian. Accessed 19 August 2019. https://bit.ly/2UXWeKe.

Malik, Kenan. Fake news has a long history. Beware the state being keeper of the truth'. The Guardian. Accessed 11 February 2018. https://bit.ly/2wRVHRR.

Packer, George. Killing Soleimani Was Worse Than a Crime. It was a blunder. Accessed 4 January 2020. https://bit.ly/2USBPWH.

Passmore, John. A Hundred Years of Philosophy. Harmondsworth, New York: Penguin, 1978.

Payne, Stanley L. The Art of Asking Questions. Princeton, New Jersey: Princeton University Press, 1973.

Plato/Platonas. Faidras/Faedrus [In Lithuanian]. Vilnius: Aidai ALK, 1996.

Rapoport, Anatol. "What Is Semantics?" In The Use and Misuse of Language, edited by S.I. Hayakawa. Greenwich, Conn: A Fawcett Premier Book, 1962.

Robson, David. The science of influencing people: six ways to win an argument, The Guardian, 30 Jun 2019. Accessed 1 July 2019, https://bit.ly/2X7XZqX.

Russell, Bertrand. An Inquiry into Meaning and Truth. Harlow: Penguin, 1965.

Stratton, Jon, 2019. Critical Thinking - a crucial $21^{\text {st }}$ century skill, accessed 8 September 2019. https://bit.ly/33Wx4iW.

"The perils of learning in English." The Economist, accessed 29 February 2019, https://econ.st/3dMDh5t.

"The steam has gone out of globalization." The Economist. Accessed 24 January 2019. https://econ.st/3aAQ71l.

Williams Zoe. "How language duped us into austerity." The Guardian. Accessed 18 February 2018. https://bit.ly/33Z8LRH. 
Wehmeier, Sally (Ed.). The Oxford Advanced Learner's Dictionary, $7^{\text {th }}$ edition. AS Hornby. Oxford, New York: Oxford University Press, 2005.

Zabulis, Henrikas. The Aesthetics of Classical Antiquity. MS A Course of Lectures. [In Lithuanian]. Vilnius: Vilnius University, 1995.

Zabulis, Henrikas. The Rhetoric of Classical Antiquity. MS A Course of Lectures. [in Lithuanian]. Vilnius: Vilnius University, 1995.

"12 Famous Philosophers and Their Guiding Principles." Invaluable. Accessed 11 June 2019. https://bit.ly/3dHbdjX. 
